\title{
Cardowan coal mine explosion: experience of a mass burns incident
}

\author{
C ALLISTER, G M HAMILTON
}

\section{Summary}

A coal mine explosion 1700 feet $(516 \mathrm{~m})$ underground and two miles $(3.2 \mathrm{~km})$ from the pit head resulted in 40 casualties. Two hours elapsed between the explosion and the arrival of patients at hospital. Six patients suffered mechanical injuries, only one of which was life threatening. Thirty six suffered burns; in 18 over $15 \%$ of the total body surface area was affected. Nineteen patients had a mild respiratory upset requiring oxygen treatment. The average length of inpatient stay in those admitted was 24 days. Early assessment and treatment in the accident and emergency department was relatively simple because of the large proportion of burn injuries. Lack of communication between site and hospital made administration of the disaster difficult.

\section{Introduction}

At 8 am on 27 January 1982 there was an explosion at the VI5 face of Cardowan Colliery, which is six miles $(9.6 \mathrm{~km})$ from central Glasgow. The VI5 face lies 1700 feet $(576 \mathrm{~m})$ below ground and two miles $(3.2 \mathrm{~km})$ south east of the pit head. At the coal face the miners worked in a space 3 feet high by $10 \mathrm{feet}$ wide by 600 feet long $(0.9 \times 3.0 \times 182 \mathrm{~m})$. The explosion ap\footnotetext{
Accident and Emergency Department, Glasgow Royal Infirmary,
Glasgow G4 0SF

C ALLISTER, BSC, FRCS, senior registrar

G M HAMILTON, MB, CHB, registrar

Correspondence to: $\mathrm{Mr} \mathrm{C}$ Allister.
}

Distribution of serious injuries in patients from Cardowan Colliery

\begin{tabular}{lccc}
\hline \multicolumn{1}{c}{ Injuries } & $\begin{array}{c}\text { Royal } \\
\text { Infirmary }\end{array}$ & $\begin{array}{c}\text { Western } \\
\text { Infirmary }\end{array}$ & $\begin{array}{c}\text { Victoria } \\
\text { Infirmary }\end{array}$ \\
\hline Head injury & $2(1$ severe $)$ & 2 & 0 \\
Burns: & 7 & 7 & 5 \\
$\quad 14$ " body surface & 70 & 3 & 0 \\
$15-34$, body surface & 10 & 3 & 0 \\
$\geqslant 35$, body surface & 1 & \\
\hline
\end{tabular}

parently resulted from a build up of methane gas to explosive concentrations.

At 920 am the accident and emergency department at Glasgow Royal Infirmary was alerted to expect eight casualties from the explosion. It was not clear how many and what type of casualties there might be. It was known that 200 men were underground when the explosion occurred. At this stage full major accident procedures were not instituted but the casualty ward was cleared of patients, the resuscitation area prepared, and that day's sessions in the fracture clinic, which is adjacent to the accident and emergency department, cancelled.

\section{Arrival of patients}

The first group of eight casualties arrived together in one ambulance at $1010 \mathrm{am}$. Thereafter ambulances containing four to eight patients each arrived every 10 to 15 minutes. By 11 am 24 patients had arrived but there was still no information on the total number of casualties. We therefore arranged to have further casualties taken to the neighbouring second line hospital. Despite this, some patients continued to arrive at the Royal Infirmary and those whose condition was judged to be satisfactory were transferred. In total, 40 miners were injured: of the 29 taken initially to the Glasgow Royal Infirmary eight were transferred to other hospitals. Eleven patients were taken directly to the Western Infirmary, Glasgow. Seven patients with minor burns, contusions, and lacerations were discharged on the day 
of injury. Thirty three patients were admitted. The table shows the distribution of patients and injuries.

\section{Accident and emergency department management}

Treatment in the accident department consisted of burns first aid. Only one patient suffered severe non-thermal injury. He had a severe head injury and was transferred to the regional neurosurgical unit after his general condition had been stabilised. In the burnt patients the size of the burn was roughly assessed and if greater than $10^{\circ} \%$ of body surface area an intravenous infusion was started. Some patients were breathless and oxygen was given empirically by face mask. If the patient was distressed intravenous narcotics were titrated against pain. Cold chlorhexidine soaks were applied to the surface of the burn. Four patients were admitted to the regional burns unit, three to the respiratory intensive care unit, and the remaining 13 to the casualty ward.

\section{Management in the casualty ward}

Further management was similar in the casualty ward, intensive care unit, and the burns unit. By $1 \mathrm{pm}$ all patients had been admitted and reassessed in consultation with staff from the regional burns unit. Reassessment consisted of re-examination of the burns and accurate estimation of their size. Those with burns to more than $15 \%$ of the body surface area (according to Wallace's rule of nines) were treated as "shock cases" and given plasma according to the formula of Muir and Barclay. ${ }^{1}$ Thirteen patients were resuscitated with plasma. Pulse, blood pressure, and urine output were monitored in all patients.

All patients had carboxyhaemoglobin, haemoglobin, and packed cell volume levels estimated, and arterial gas tensions were also measured in those who were dyspnoeic. Oxygen was administered by face mask according to the arterial gas results. No significant rise in carboxyhaemoglobin levels was found. ${ }^{2}$ There were no patients with oropharangeal burns. Eye irritation was an indication for instillation of fluorescein, but no corneal burns were found. Most patients had considerable swelling of the eyelids and in these patients chloromycetin eye drops were used. Specific treatment of burnt surfaces consisted of deroofing the blisters; facial burns were exposed and burns of the trunks and arms were dressed with silver sulphadiazine cream. Burns of the hand were raised and mobilised in plastic gloves with silver sulphadiazine.

Patients with serious burns were transferred to a ward made available at the regional plastic surgery unit when their condition had stabilised-that is, between 48 hours and one week in most cases. Further dressings, nursing care, and, when necessary, skin grafting were carried out there.

\section{Injuries}

We have examined the case notes of all the patients injured in this accident. There were no deaths and all the patients were men. The average age was 40 (range 20-59).

\section{MECHANICAL INJURIES}

One patient suffered minor wounds requiring suture. Three suffered contusions of the trunk and legs. Four had head injuries: two suffered mild concussion, one a linear compound vault fracture, and one a severe head injury (see above); the patient with the severe injury eventually made a surprisingly good recovery but was left with a residual speech deficit and hemiparesis.

\section{THERMAL INJURIES}

Thirty six patients suffered burns, of which none appeared to be full thickness: 18 had burns of less than $15 \%$ of the body surface area, 14 had burns of $15-34 \%$, and four had burns of $35-55^{\circ} \%$. Thirty four patients had burns of the hands, face, and neck. Seventeen patients also had burns of the shoulders and upper trunk, and they accounted for most of the severe burns.

\section{RESPIRATORY DYSFUNCTION}

Nineteen patients were treated with oxygen. No one required mechanical ventilation. The respiratory dysfunction consisted of mild to moderate arterial hypoxacmia. The lowest arterial $\mathrm{Po}_{2}$ measured was $11.7 \mathrm{kPa}\left(35 \mathrm{~mm} \mathrm{Hg}\right.$ ). The $\mathrm{PCO}_{2}$ in these patients was minimally lowered. The chest radiographs were all normal, and the only abnormal findings on examination of the chest were occasional scattered crepitations and rhonchi. The hypoxaemia was maximal at 24 hours after the explosion and settled over $48-72$ hours.

\section{Operations and complications}

Six patients required split skin grafting to their burns. This was carried out two to three weeks after the explosion. One patient had a major upper gastrointestinal bleed and required a laparotomy to oversew a bleeding gastric ulcer. The average length of stay for the burnt patients was 24 days (range $8-78$ ).

\section{Discussion}

Recent reviews of disaster planning have emphasised the restriction of treatment in the accident and emergency department to urgent measures, with the aim of stabilising the patient's condition, and early transfer to a ward where reassessment can take place. ${ }^{3}$ The mass burns incident fits this approach very well. Glasgow Royal Infirmary contains the regional burns unit and most of the staff in the accident and emergency department are cognisant of the assessment and resuscitation regimen for burns patients. Most patients from this explosion had suffered burns and as this combination allowed rapid treatment in the accident department most patients were treated and transferred from the accident department within about 20 minutes.

Incidents producing $25-100$ casualties have been classified by Rutherford as minor or grade I disasters. ${ }^{5}$ Such disasters are likely to stress the organisation of a single hospital. We found that dealing with these 29 patients did not unduly stress the hospital organisation despite the fact that all but one patient were admitted. There was no need to mobilise the resources of the entire hospital. Patients were, however, transferred to second line hospitals as at this stage the total number of casualties had not become apparent.

The major management problem resulted from the lack of information coming from the site of the accident. Communications underground were non-existent, and therefore the ambulance controller at the pit head had little or no advance information about the number or severity of those injured. His priority was to transfer patients as quickly as possible to hospital. A site medical officer would therefore have provided no additional benefit.

Initially we attempted to perform triage at the front door of the accident and emergency department. Patients with severe burns, however, were found to be walking into the department while patients with relatively minor injuries were brought in on stretchers and trolleys. Attempts at sorting out these patients when six or eight arrived simultaneously were found to be impractical and were abandoned. Of those who were quickly assessed and then redirected to other hospitals, it was subsequently confirmed that their injuries had been minor. Eleven patients were taken directly to other hospitals.

The disturbances in respiratory function were mild and never life threatening. In retrospect, estimation of carboxyhaemoglobin concentrations was probably of no value because all of the men had used their respirators, which specifically extract carbon monoxide. With the paucity of clinical findings it has been impossible to distinguish whether the respiratory dysfunction resulted from the blast injury or from an inhalation of the toxic products of combustion.

Three previous coal mine explosions have been reported. ${ }^{6}$; An explosion at Brookhouse Colliery in 1958 resulted in 44 injured and dead. Similar incidents resulted in 37 casualties at 
Huckton Valley in 1962 and in 24 at Bethnal Mine, Lanarkshire, in 1969. The proportion of dead to injured appears likely to be related to the power of the explosion, which is, in turn, related to many factors, including the relative proportion of oxygen and combustible gases in the mine and the configuration of the area in which the explosion occurs. The fact that the roof was low and that most of the miners were either lying or crouching at the time of the explosion probably contributed to the small number of mechanical injuries and absence of deaths at Cardowan Colliery.

Fortunately most patients had burns injuries that were relatively easily managed in the accident department. We accept that if there had also been several patients with multiple injuries or critically injured patients then efficient management in the accident department would have been much more difficult, requiring the mobilisation of many more staff. After the publicity given by the media, we noted that fewer individuals attended the accident and emergency department with trivial conditions, resulting in an overall reduction in the department's workload for several weeks.
We thank Mr W H Reid who allowed us to examine the notes of the patients under his care.

\section{References}

${ }^{1}$ Muir IFK, Barclay TL. Treatment of burns shock. In: Burns and their treatment. London: Lloyd-Luke, 1962:26-32.

2 Clark CJ, Campbell D, Reid WH. Blood carboxyhaemoglobin and cyanide levels in fire survivors. Lancet $1981 ; \mathrm{i}: 1332-5$.

${ }^{3}$ Williams DJ. Major disasters: disaster planning in hospitals. $\mathrm{Br} \mathcal{F} \mathrm{Hosp}$ Med 1979;22:308-22.

4 Yates DW. Major disasters: surgical triage. Brf Hosp Med 1979;22:323-8.

${ }^{5}$ Rutherford WH. Disaster planning. In: Rutherford WH, Nelson PG Weston PAM, Wilson DH, eds. Accident and emergency medicine. London: Pitman Medical, 1980:37-8.

${ }^{6}$ Rutherford WH. Experience in the accident and emergency department of the Royal Victoria Hospital with patients from the civil disturbances in Belfast 1969-1972, with a review of disasters in the United Kingdom 1951-1971. Injury 1973;4:189-99.

7 Sillar W, Bainbridge C. Disaster. Report on visit to North America. Glasgow: Greater Glasgow Health Board, 1974.

(Accepted 6 May 1983)

\section{MATERIA NON MEDICA}

\section{Off beat bar}

The Bar Naranja in the southern Spanish city of Murcia is sited inauspiciously even for a southern Spanish bar. It is surrounded by acres of dusty waste ground, which in turn are surrounded by architecturally undistinguished high rise flats. The track to the bar is heavily rutted and unsigned, and its exact position was the subject of noisy disputation between my Spanish hosts. We came to a halt in the rock strewn car park, and the immediate prospect was no more inviting: a tall, chain linked fence surmounted by barbed wire, surrounding a tree filled compound.

As we left the car, though, two things were immediately out of place. One was the richly perfumed air; the other was the Mozart coming from the tannoys on the trees. The entrance to the bar is by a whitewashed wall on which are the following statements, or commands: "This is the Bar Naranja. It is forbidden to be indifferent. The music is sacred or classical. Everyone must eat something. Everyone must pay 200 pesetas." Inside the gate, a man handed the leader of our group blank pieces of paper. The surreal atmosphere was heightened by pungent smell of thyme and of hundreds of cut carnations. The bar is largely open air, and the chill of the Spanish December night was reduced by the scores of beeswax church candles mounted in ornate ecclesiastical candelabra which lit the paths between tables, and the alarming open pits of blazing charcoal which dotted the pathways, their edges barely above the level of the paving slabs. The floors were covered with sprigs of thyme, which gave off their characteristic herbiness when crushed underfoot, or when tossed into the fires.

The tables are separated by various extraordinary architectural features: the small, blue tiled, floodlit swimming pool, with classical statuary; an ornamental fountain in a giant clam shell, the water of which forms a paddling pool for three Australian black swans; vast piles of lemons, oranges, grapes, melons, and water melons, and everywhere elaborate floral displays.

Our path took us to one end of the compound, where the owner has created a sort of miniature crystal palace, a large greenhouse with a curved roof, at the end of which is an immense baroque marble altarpiece, complete with androgynous Blessed Virgin and angels, the whole surmounted with velvet drapes, gilt framed mirrors, and explosions of scarlct carnations. At the base runs a small waterfall, skilfully lit from below. At the other end of the compound is the ancient farmhouse, stuffed with baroque cabinets which are filled in turn with religious or classical statuary of an ornate and frankly hideous nature. The loos are, needless to say, of marble and contain, curiously, vast bath tubs.

The drinks (and, yes, the bar has drinks, too) are also theatrical. Our party drank the sweet wine. This turned out to be an extraordinary muscatel of amazing richness of colour and honeyed bouquet. The food that came with the drinks was a large salad of the local fruit. The clientele seemed strangely subdued, despite their youth and beauty. Perhaps they were remembering other evenings at La Naranja, such as the time when the owner covered the water in the swimming pool with olive oil and threw in a thousand lighted wicks to create an extraordinary waterborne candle, and then layered the floor with rose petals to celebrate the Feast Day of the Blessed Virgin.-TERENCE CUBITT, Alton, Hants.

\section{"Take suggestion as a cat laps ..."}

One fine morning she appeared in our home and after meals she would disappear into the attic. No attempt was made to befriend any of the family members. After a couple of weeks, during which period my children had entertained suspicions of faint cries emanating from the attic, she brought her kittens down to be introduced formally to the human family. Probably her clinical evaluation of it confirmed her suspicion that we were fit and proper to be adopted. Affection between my children and hers was mutual and they shared the bed and the playthings, but parental authority had to be used at sharing the food plate.

Months passed by and the number of cats increased. During one delivery there was only one kitten and this died after a few days. The mother cat brought the kitten down and laid it at my wife's feet and started crying pathetically. Why did she choose my wife and not me or my sons for sharing the grief? Did she recognise the sex or is it because my wife was the one who often supplied the food?

Watching the cats is fun but the above instance tickled my curiosity regarding their behaviour. When kittens are born, for the first few weeks the mother cat laps up all the urine from the kitten from the source. Why does she do it ? Is it to keep the environment clean since the kittens cannot run far at that stage ? Cows and dogs also are known to drink the urine of their young ones. Does nature have some balancing mechanism whereby the urine of the newborn has some hormone or chemical which will affect the mother's postdelivery period, maybe control or stimulate production of milk ?

We identify many substances in the urine. Maybe there is something in the theory of the usefulness of autourine therapy and perhaps prime ministers who practise it will have the last laugh. $-C$ K EAPEN, general physician, Little Flower Hospital, Angamally, India. 